ISSN electrónico: 2172-9077

https://doi.org/10.14201/fjc201714215227

\title{
BRICOLAGE Y PARODIA EN LA CULTURA DE LA CONVERGENCIA
}

\section{Bricolage and Parody in Convergence Culture}

\author{
Dr. Javier MORAL MARTÍN \\ Profesor Asociado Universidad Politécnica de Valencia, España \\ E-mail: javier.moral.martin@gmail.com \\ (D) http://orcid.org/0000-0001-5498-4883
}

Fecha de recepción del artículo: 05/12/2016

Fecha de aceptación definitiva: 28/03/2017

\begin{abstract}
RESUMEN
En la cultura de la convergencia, las prácticas audiovisuales colaborativas han sido comprendidas habitualmente como un ejercicio situado entre lo amateur y lo profesional. Dicha caracterización conlleva implícita una infravaloración de lo amateur ya que, en una misma jerarquía de ordenación, es considerado como un escalón preliminar y más imperfecto de lo profesional.

Por el contrario, si recurrimos a las categorías del bricolage analizadas por Levi Strauss, lo amateur y lo profesional se constituyen como elementos de un eje plenamente semántico. Este cambio de perspectiva tiene importantes consecuencias: por un lado, permite valorar hasta qué punto dichas prácticas pueden alterar las dinámicas productivas de las prácticas audiovisuales profesionales y, por otro, ayuda a comprender mejor la especificidad textual de las prácticas colaborativas, de manera privilegiada esa gran categoría dialógica que es la parodia, género esencial en las dinámicas bottom-up que inundan nuestro universo audiovisual.
\end{abstract}

Palabras clave: Cultura de la convergencia; parodia; bricolaje; fanfilm.

\begin{abstract}
In Convergence culture, collaborative practices have been commonly understood as exercises located between the amateur and the professional. This characterization involves an implicit underestimation of amateurism because, in a single organization hierarchy, is considered as a preliminary step to the professional world and, therefore, a more imperfect activity.

However, if we draw on the categories of bricolage analyzed by Levi Strauss, amateurism and professionalism are constituted as elements of a semantic axis. This shift in the analysis perspective has important consequences: on the one hand, it makes it possible to assess how many of these practices can alter the productive and textual dynamics of professional audiovisual practices and, on the other hand, it helps to better understand the textual specificity of collaborative practices, especially the great dialogical category of parody, an essential genre in the bottom-up dynamics which exist in our audiovisual universe.
\end{abstract}

Key words: Convergence culture; parody; bricolage; fanfilm. 


\section{INTRODUCCIÓN}

Las profundas modulaciones que están redefiniendo el entorno de las industrias culturales contemporáneas han afectado a las tradicionales formas de producción y distribución de los productos audiovisuales. La proliferación de nuevos canales de difusión y la entrada en liza de potentes plataformas de contenido online como Netflix, Wuaki, Filmin, etc., el abaratamiento de los costes de producción derivado de la masiva utilización de las tecnologías digitales, así como la cada vez más habitual creación de redes colaborativas de trabajo, están redibujando, no solo la tradicional geografía audiovisual, sino también y sobre todo nuestra concepción de un mundo dominado por la imagen. Esa suerte de pantalla global descrita por Lipovetsky y Serroy (2009), así como los nuevos tipos de imagen que define -Imagen-exceso, Imagen-multiplejidad e Imagen-distancia-, interpelan al espectador de una manera particular y diferenciada de otros momentos históricos.

La caracterización general elaborada por el profesor y teórico Henri Jenkins en su conocido trabajo sobre la cultura de la convergencia, sigue vigente en la caracterización de unas dinámicas comunicativas y productivas audiovisuales asentadas en una doble tendencia confrontada:

Por un lado, las tecnologías de los nuevos media han rebajado los costes de producción y distribución, han expandido el abanico de canales de difusión disponibles y han permitido a los consumidores archivar, anotar, apropiarse y hacer recircular contenido de nuevas y potentes formas: por otra parte, se ha ido produciendo una alarmante concentración de la propiedad de los principales media comerciales, de forma que un pequeño grupo de conglomerados mediáticos multinacionales domina todos los sectores de la industria del entretenimiento. (Jenkins, 2004, p. 33).

La polarización, pues, parece dominar nuestra realidad icónica (aunque la coincidencia de intereses permita la cohabitación cuando no abierta convergencia entre ambas orillas como en el caso de la saga Star wars y Matrix). Por un lado, fenómenos ligados a la emergencia de una cultura participativa en la que el usuario -o redes de usuarios- disponen de múltiples recursos para generar contenidos y proyectos audiovisuales. Así, del rol pasivo descrito por las teorías comunicativas clásicas, sujeto meramente receptor de un discurso unidireccional emitido por una instancia comunicativa, se ha pasado a un espectador activo que se arroga algunas características del creador de contenidos. Se trata de un sujeto que ha mutado de una originaria condición de consumidor a la de «prosumidor» (productor + consumidor).

En la orilla de enfrente se sitúan los grandes conglomerados que no son ajenos a esta situación. Amenazados por la proliferación de pequeñas producciones que acaban arrastrando a millones de espectadores, estos nuevos gigantes buscan la complicidad con esos otros medios y modelos productivos mediante la atención y atracción de los potenciales consumidores. De manera ejemplar a través de los departamentos de marketing, que buscan mantener el interés de las comunidades de fans y su incorporación en algunos de los procesos previstos por el proyecto. En ese sentido, Matrix (hermanos Wachowski, 1999-2004), en su despliegue en numerosos formatos y canales, sigue funcionando como paradigma de la narrativa transmedia analizada por Jenkins (2006, p. 100): «Matrix es un entretenimiento para la era de la convergencia mediática, integrando múltiples textos para crear una narración de tales dimensiones que no puede confinarse a un único media». Está la trilogía fílmica, pero también diversos videojuegos, una serie de cómics y de animación, a lo que hay que añadir las innumerables producciones desarrolladas por los fans de la saga que expanden el universo audiovisual de Matrix. 
No obstante, para poder sancionar en su justa medida este nuevo estado de cosas, conviene no perder de vista su inscripción en unos procesos históricos más amplios que aporten una visión general de los procesos de creación audiovisual. En ese sentido, digámoslo claro, la propia naturaleza de los proyectos audiovisuales implica la participación obligatoria de múltiples talentos. Incluso en esa gran maquinaria engrasada que fue el Hollywood de las décadas centrales del s. XX, resultó necesaria la intervención de diversos agentes. De hecho, la conocida metáfora de la fábrica de sueños, pone de relieve la colectividad en la realización del producto final. Comenzando por el productor, al que siguen los directores, guionistas, camarógrafos, etc., que en no pocas ocasiones establecían unos grupos de trabajo muy estables y especializados en géneros concretos. Otro tanto podría decirse de la toma de decisiones del espectador en la versión definitiva de las películas: sobradamente conocidas son las encuestas que realizaban las Majors en sus preestrenos.

Es más, que la película esté firmada por un director, no es más que una reducción operativa. De hecho, la noción del autor fue una conquista de la modernidad que contradecía de manera abierta lo que para el studio system había sido la norma; conquista además que, como señaló Santos Zunzunegui (2008, pp. 205-206), ponía entre paréntesis «cualquier referencia a la dimensión colectiva de la obra cinematográfica para tratar al cineasta (al director) como autor total, de idéntica forma a la que se había venido tratando al escritor, al pintor o al músico».

Pero también en los márgenes, e incluso en la radical exterioridad de Hollywood, existieron diversas propuestas que pueden ser analizadas desde una perspectiva colaborativa más contemporánea. De hecho, a la vez que el studio system se organizaba según los criterios de cadena de montaje, las dos vanguardias -blanca y roja- proponían su propia consideración de lo cinematográfico en virtud de una impugnación de las bases literarias clásicas, así como de una reconsideración de los procesos producti$\operatorname{vos}^{1}$. En el terreno de aquella vanguardia blanca de la década de los años 20 en que numerosos artistas plásticos se acercaron al nuevo medio de expresión, puede anotarse el conocido caso de Entracte (1924) de René Clair y Francis Picabia, que contó con la activa colaboración de lo más granado del surrealismo y el dadaísmo: Marcel Duchamp, Man Ray o Erik Satie, responsable de la banda sonora ${ }^{2}$. La vanguardia roja también dio notables ejemplos como algunas producciones anarquistas en el contexto bélico español ${ }^{3}$, o el film colectivo frentepopulista impulsado por un joven Jean Renoir: La vie est à nous (1936).

Así pues, el desarrollo y la culminación de proyectos audiovisuales entendidos como una sinergia desjerarquizada de flujos y agentes no es un fenómeno reciente. En todo caso, la principal diferencia que podría anotarse respecto a la actualidad radica, por un lado, en la permeabilidad entre la producción y la recepción, y por otro, la visibilidad de estos nuevos fenómenos en el universo audiovisual con el paso de la marginalidad al centro o, mejor dicho, su expansión por todos los rincones de una cartografía audiovisual que se ha quedado sin centros. En resumidas cuentas, lo que ha cambiado como señaló Jenkins, «es la visibilidad de la cultura de los fans» (2006, p. 137). Y en ello ha tenido mucho que ver, qué duda cabe, la irrupción de las nuevas tecnologías y la Web (de manera especial su versión 2.0), infinito contenedor audiovisual que ha posibilitado «que producciones alternativas de todo tipo hayan adquirido mayor visibilidad, dando espacio a diversos grupos minoritarios para contar sus propias historias o cuestionar representaciones hegemónicas de su cultura» (Roig, 2009, p. 92).

\footnotetext{
${ }^{1}$ Sobre las dos vanguardias y su progresiva cercanía a lo largo de los años 70, consúltese (Wollen, 1988).

${ }^{2}$ Sobre el cine de las primeras vanguardias y Entr'acte, consúltese (Berteto, 1983).

${ }^{3}$ Para una mayor profundización en el tema, consúltese la Tesis doctoral de Pau Martinez (2008).
} 


\section{CAMBIANDO DE PERSPECTIVA: DE LO CINEMATOGRÁFICO A LO FÍLMICO}

Pero más que analizar la redefinición de los roles y las nuevas dinámicas industriales que implica, estas páginas pretenden evaluar la incidencia de dichos cambios en la corporeidad de las propuestas colaborativas. Esto es, profundizar en sus particularidades expresivas y estilísticas, comprobar si esta participación implica unos cambios en las formas audiovisuales -narrativas, temáticas y enunciativasrespecto a los paradigmas asentados en el universo cinematográfico o, por el contrario, no son más que espejos imperfectos del mismo.

Para ello, quisiera traer a colación un debate que resultó crucial para la evolución del pensamiento y la teoría sobre el cine, pero que puede aplicarse, por extensión, a cualquier práctica audiovisual. A la cabeza de dicho debate se situó Christian Metz que, en su clásico Lenguaje y cine (1973) se apropió, aunque reformulándola, una oposición establecida por Gilbert Cohen-Seat en Essai sur les príncipes d'une philosophie du cinéma: «hecho cinematográfico» frente a «hecho fílmico». Así, por hecho cinematográfico, Metz (1973, p. 39) distinguía aquel conjunto de hechos que se manifiestan antes de la película (infraestructura económica, legislación, sociología, tecnología de los aparatos, biografías de los cineastas, etc.), después de la película (reacciones de los espectadores, encuestas de audiencias, etc.), y durante la película, pero en su exterioridad (equipo de las salas, modalidades técnicas de la proyección, función del acomodador, etc.). Frente a este conjunto de hechos se encontraría el hecho fílmico, nivel que permite distinguir al filme como un objeto más limitado, designado de manera preliminar por Metz como «un discurso significante localizable» (Metz, 1973, p. 31). La semiología, por tanto, considera el filme como un lenguaje y su objetivo consiste en analizar cómo significa dicho discurso ${ }^{4}$.

Lo que interesa retener aquí de esta distinción esencial, válido también para la comprensión de nuestro complejo presente audiovisual, es que parece evidente que la mayor parte de trabajos académicos que han valorado dicha emergencia colaborativa se han centrado básicamente en el nivel del hecho cinematográfico, desestimando unos modos analíticos más pegados a la corporeidad de los artefactos audiovisuales resultantes. Una situación que está determinada, por un lado, por la pérdida de atracción intelectual de la semiología y la semiótica en detrimento de otras perspectivas analíticas más contextuales, y por otro (aunque complementario de lo anterior), porque dicha perspectiva contextual parece en principio más fructífera a la hora de abordar el nuevo fenómeno.

En ese sentido, resumiendo y dicho de manera algo precipitada, la inmensa mayoría de películas que se circunscriben al universo de lo «colaborativo» resultan extremadamente provechosas en cuanto hecho cinematográfico, pero presentan un escaso valor en cuanto hecho fílmico. Y es que, si nos concentramos en sus valores formales, los resultados parecen pobres y, sobre todo, apenas diferentes del cine realizado en el seno de la gran industria. Es más, una inmensa mayoría se reconoce en las estrategias retóricas de los grandes blockbusters a los que invocan (no en vano, muchos de sus autores no ocultan que se tratan de intentos por formar parte de la industria como ha puesto de relieve Barbara Klinger, 2006).

Dos emblemáticos ejemplos servirán para ilustrar dicha afirmación. En cuanto hecho cinematográfico, Born of hope $e^{5}$ se presenta como un clásico ejemplo de fanfilm a partir de estrategias de crowdsourcing $^{6}$. El proyecto fue iniciado en 2003 por la cineasta británica Kate Madison, cuya intención residía en presentarlo a la Tolkien Fan Film Exbibition. La propuesta originaria fue creciendo, y la cineasta consiguió concitar a su alrededor a cientos de fans de todas las partes del mundo, que tomaron diversas

\footnotetext{
${ }^{4}$ Perspectiva que no agota desde luego el objeto mismo, el filme, que puede ser analizado también en virtud de otras perspectivas como la sociología, la narratología, la estética, la psicología o el psicoanálisis.

${ }^{5}$ Consultado en: http://www.bornofhope.com/.

${ }^{6}$ Sobre el fenómeno fanfilm, consúltese (Jenkins, 1992). Respecto a las prácticas relacionadas con el crowdsourcing y crowdfunding, consúltese (Roig, 2012).
}

(C) Ediciones Universidad de Salamanca / CC BY - NC ND Fonseca, Journal of Communication, n. 14, 2017, pp. 215-227 
decisiones a lo largo de todo el proceso: sobre el atrezo, el casting, la banda sonora, el guion, y algunos llegaron incluso a trabajar como actores en el film sin cobrar nada a cambio. Asimismo, la financiación se consiguió mediante aportaciones privadas a través de la web del proyecto. El film se estrenó finalmente en 2009 y se distribuyó de manera gratuita por internet.

Sin embargo, en cuanto hecho fílmico, Born of hope se propone como una mera continuación del universo ideado por el escritor J. R. R. Tolkien. De hecho, las acciones y personajes que relata proceden del Apéndice A de El Señor de los Anillos y se sitúan en un tiempo anterior al de la novela ${ }^{7}$. Como trasfondo del relato, la sempiterna lucha entre el bien y el mal que vertebra la conocida saga literaria. Pero la fidelidad al universo tolkiano es a su vez simétrica a la manufactura audiovisual del eficaz Peter Jackson y su conocida trilogía. Al margen de las limitaciones impuestas por el presupuesto, paliadas en no pocas ocasiones con altas dosis de imaginación, la caracterización de los seres y monstruos que habitan la narración, la reconstrucción de los parajes y su condición de marcada tonalidad romántica, beben directamente del imaginario del cineasta neozelandés.

Idéntica valoración puede hacerse de otro clásico ejemplo de cine colaborativo, en este caso español, que es El cosmonauta (2013). Si en cuanto hecho cinematográfico presenta los rasgos propios de un proyecto que aúna crowfunding y narración transmedia (generación de una entregada comunidad de usuarios que mediante su participación activa ha permitido su financiación y proyección en las redes sociales, o su distribución alternativa en internet bajo la licencia de Creative commons que permite el remontaje), en cuanto hecho fílmico, el film de Nicolás Alcalá, Carola Rodríguez y Bruno Teixidor, es un claro homenaje al cine moderno encarnado de manera magistral por el cineasta ruso Andreas Tarkovski. La vocación de trascendencia y los momentos sensoriales del film, cuyos primorosos primeros planos se desentienden del flujo narrativo para constituirse en puras imágenes que se dan a ver, la convocación de universos paralelos que se entrelazan sin una jerarquía clara y estable, el misterio que impregna las imágenes y dejan al espectador sin los vínculos que le permitan clausurar el relato, se nutre directa y explícitamente de ese cine del ensueño que es la marca de películas como El espejo (Zerkalo, 1975), Solaris (Solyaris, 1972), Stalker (1979), Nostalghia (1983) o Sacrificio (Offret, 1986).

\section{ESTÉticA BRICOLAGE Y CULTURA DE LA CONVERGENCIA}

No obstante, si hubiera que destacar un rasgo o gesto que, en cuanto hecho fílmico, distanciara a algunos de estos artefactos audiovisuales de las películas manufacturadas en el entorno más industrial, tendría que ver con esa cualidad anotada por numerosos autores que sitúan a las prácticas colaborativas a mitad de camino entre lo amateur y lo profesional o, en términos de Henry Jenkins (2006), entre lo aficionado y lo profesional.

Sin embargo, dicho eje resulta problemático al constituirse según una distinción de tipo cuantitativo que concibe lo primero (lo amateur) como un paso poco desarrollado respecto al segundo (lo profesional). Aquel sería por tanto un escalón preliminar y más imperfecto de este en una misma jerarquía de ordenación: de lo mal hecho a lo bien hecho, del desconocimiento de las reglas que sustentan determinada actividad, a su perfecto control y manejo según unos estándares reconocidos «globalmente». Ni que decir tiene que dicha caracterización conserva de manera implícita una infravaloración de los artefactos colaborativos en virtud de una apreciación determinada por el punto de vista profesional que, en todo caso, pone en valor aquellos ejemplos más próximos a los estándares industriales (tal es el caso, por ejemplo, de la reconocida Revelations, Shane Felux, 2005).

\footnotetext{
${ }^{7}$ En concreto, se encarga de dar forma a la historia de los padres de Aragorn, y su lucha para evitar que muera su hijo, el último descendiente del linaje de Elendil.

(C) Ediciones Universidad de Salamanca / CC BY - NC ND Fonseca, Journal of Communication, n. 14, 2017, pp. 215-227
} 
Es por eso que tal vez resulte más pertinente, y también mucho más fértil, utilizar otro término parecido (aunque no estrictamente sinónimo), que Levi-Strauss reintrodujo en el ámbito de la antropología estructuralista: el bricolage, ya que permite valorar el par amateur/profesional en términos de distinción cualitativa. No en vano, para el antropólogo, el pensamiento mítico que opera mediante el bricolage no es una manera «primitiva» respecto al pensamiento científico, sino otro modo diferente de comprender el mundo: en lugar de ordenarlo a partir de términos racionales, lo hace en virtud de una ordenación en términos sensibles, es decir, a partir «de la organización y de la explotación reflexiva del mundo sensible en cuanto sensible» (Levi-Strauss, 1997, p. 35).

La distinción entre esos dos saberes sería por tanto categórica y no de tipo relacional como la que se instituye entre lo amateur y lo profesional: los dos términos se instituyen así como elementos de un eje plenamente semántico. Este cambio de prisma permite extraer determinados rasgos específicos del bricolage sobre los que merece la pena reflexionar. En especial, la diferencia que se instituye entre el modus operandi del bricoleur y el del hombre de ciencia que ejemplifica el ingeniero:

El bricoleur es capaz de ejecutar un gran número de tareas diversificadas; pero, a diferencia del ingeniero, no subordina ninguna de ellas a la obtención de materias primas y de instrumentos obtenidos a la medida de su proyecto: su universo instrumental está cerrado y la regla de su juego es siempre la de arreglárselas con 'lo que uno tenga', es decir un conjunto, a cada instante finito, de instrumentos y de materiales, heteróclitos además, porque la composición del conjunto no está en relación con el proyecto del momento, ni, por lo demás, con ningún proyecto particular, sino que es el resultado contingente de todas las ocasiones que se le han ofrecido de renovar o de enriquecer sus existencias, o de conservarlas con los residuos de construcciones y de destrucciones anteriores. (Levi-Strauss, 1997, p. 36).

Por tanto, a diferencia del ingeniero que construye los instrumentos con los que proyectar un objeto de conocimiento (en virtud de la verificación de una estructura preestablecida: las hipótesis y teorías que sustentan dicho proyecto), el bricoleur no elabora unos instrumentos específicos ni trabaja con materias primas, antes bien, trabaja con «sobras y trozos» ya elaborados que recoge y conserva según el principio de que «de algo habrán de servir». De ahí la predeterminación ejercida por los instrumentos y materiales que utiliza, y que coaccionan el resultado en una medida mucho mayor que al ingeniero: el bricoleur no puede desestimar la procedencia y la función desempeñada por ellos. Y de ahí también que, como expusiera Levi-Strauss (1997, p. 40), el bricoleur trabaje con imágenes y signos ya constituidos en lugar de con conceptos: «el concepto se nos manifiesta como el que realiza la apertura del conjunto con el que se trabaja, y la significación como la que realiza su reorganización: no la extiende ni la renueva, y se limita a obtener el grupo de sus transformaciones». Por eso puede decirse que la operatividad del bricolage es siempre contingente, no está sujeta a la premisa de un proyecto rector, antes bien, el resultado de dicha operación puede variar conforme se incorporan nuevos materiales.

Si trasladamos la argumentación del antropólogo al terreno de las prácticas colaborativas audiovisuales, parece factible el establecimiento de una homología entre lo profesional y lo científico de un lado, y lo amateur y el bricolage por otro. Tal es la hipótesis que sustenta esta investigación: gran parte de las producciones anónimas que pueblan nuestro universo icónico se constituyen como explícitos ejercicios que reorganizan signos audiovisuales precedentes. Pero no deben considerarse como artefactos imperfectos, sino como auténticos ejercicios intertextuales que, manifestando su diferencia, se constituyen a partir de su confrontación con los textos referentes. 
No en vano, basta con echar un somero vistazo a la superficie textual de las numerosas webs especializadas en fanfiction y fanfilm ${ }^{8}$ o de ese infinito cajón de sastre que es YouTube, se puede comprobar con facilidad hasta qué punto los anónimos usuarios operan como auténticos bricoleurs. Al igual que estos, los grupos de fans se apropian de todo tipo de residuos de obras audiovisuales que disponen como auténticos operadores de significación en la construcción de nuevos discursos basados en la reordenación de los signos que constituyen el ámbito de referencia. De esta forma, mediante estrategias propias del bricoleur -remontaje, remezcla, collage, mashup, etc.-, ponen en circulación sus propios modelos y narraciones a través de unas estrategias que adoptan diversos rostros. Por un lado, se situarían aquellos artefactos construidos a partir de la materialidad misma del discurso referente; nos encontraríamos por tanto dentro de una suerte de provincia o sub-provincia del Found footage que continuaría las experiencias estéticas y políticas de artistas como Bruce Conner o Ken Jacobs en la década de los 70, o Douglas Gordon y Mathias Müller en los 90. Por otro lado, se situarían aquellos artefactos que convocan los universos narrativos, temáticos y/o enunciativos de los textos referentes, pero que se construyen a partir de material audiovisual original. Un buen ejemplo de lo primero sería la proliferación de videos musicales que remezclan fragmentos fílmicos con composiciones de cantantes o grupos diferentes de la banda sonora original. Es el caso de la historia de amor entre los protagonistas de la saga Matrix, Neo y Trinity, que ha sido objeto de numerosas síntesis audiovisuales bajo los acordes de grupos tan variados como Coldplay, Bon Jovi, Céline Dion, Enya o Mat Kearney. Un buen ejemplo de lo segundo serían divertimentos como The Jedi Who Loved Me (2000), rodada por los invitados a un banquete de bodas que homenajeaban así a los novios, o Matrix Return': haciendo gala de una ostensible precariedad formal, escenográfica y técnica (Matrix Return se construye con una rudimentaria técnica de la pixilación que se muestra, incluso, enfáticamente amateur), tres adolescentes sintetizan en apenas dos minutos y medio de duración el universo temático de la saga de los Wachowski, utilizando para ello un relato fanfic de Peter Chimaera ${ }^{10}$.

\subsection{LAS WIKIPELIS: UN ESTUDIO DE CASO}

No obstante, para comprender mejor la hipótesis aquí expuesta, quisiera detenerme con más detalle en dos conocidos ejemplos del fenómeno colaborativo que han surgido en un entorno profesional y que, por tanto, resultan útiles para evidenciar que la estética del bricolage no es una cuestión de amateurismo tecnológico, ni de presupuesto. Me refiero a las dos wikipelis realizadas hasta el momento con el patrocinio de la marca de Mahou y que, a pesar de ampararse ambas bajo idéntico signo colaborativo, se contraponen sin embargo como dos propuestas enfrentadas en los términos descritos: reorganización de significados frente a organización de conceptos ${ }^{11}$.

La primera de ellas, titulada Universos y co-dirigida por José Corbacho y Juan Cruz junto a 3.257 usuarios, se constituye a partir de la heteróclita reunión de diversos materiales procedentes del universo cinematográfico. Se trata de géneros con escasos elementos en común a priori, que son amalgamados en virtud de una operatividad muy funcional. La definición aportada por los propios cineastas resulta reveladora de los fundamentos que guiaron el proyecto: «La peli va de un chaval que se somete a un experimento para viajar a los universos que se intuye que existen. Es un contenedor de ciencia ficción en el que hemos metido otros géneros como la acción, el terror o la comedia romántica» ${ }^{12}$.

\footnotetext{
${ }^{8}$ Entre ellas: http://ebookfriendly.com/fan-fiction-websites, https://www.fanfiction.net/.

${ }^{9}$ https: / $/$ www.youtube.com/watch? $\mathrm{v}=\mathrm{VM}$ il5inFHkc\&list=RDVMil5inFHkc\#t=44.

${ }^{10}$ https://www.fanfiction.net/s/3323569/1/The_Matrix_Return.

${ }_{11}$ Para una mayor profundización en las dos wikipelis y el fenómeno del cine colaborativo en España, consúltese (Marcos, 2013).

${ }^{12}$ Consultado en: http://www.levante-emv.com/cultura/2009/07/09/corbacho-rueda-primera-wikipeli-mundo/610172.html.

(C) Ediciones Universidad de Salamanca / CC BY - NC ND Fonseca, Journal of Communication, n. 14, 2017, pp. 215-227
} 
Amparado bajo la excusa «contenedora», todo queda encajado según un principio de frágil complementariedad: la trama se anuda en virtud de una débil codificación y el resultado tiene algo de relato frankestiniano. La prueba de la permutabilidad explicita hasta qué punto el Todo es indiferente para las partes. La alteración en el flujo sucesivo de las secuencias no afectaría al resultado final: Universos significaría exactamente lo mismo, puesta en relación de distintos fragmentos que apenas consiguen instituirse en cuanto unidad.

Aún más, la primera wikipeli decide trabajar abiertamente con la yuxtaposición contingente de unos signos procedentes de los géneros de los que derivan las secuencias, trabajando con unos «mensajes en cierta manera pretrasmitidos y a los cuales colecciona» (Levi-Strauss, 1997, p. 40) y reorganiza en el seno del nuevo discurso según las necesidades impuestas por las propias dinámicas de producción. En primer lugar, y por orden de aparición, se sirve del cine de acción: el primer viaje del protagonista se construye bajo el signo epidérmico de películas de serie B pasadas por el filtro de un cineasta como Quentin Tarantino. El paisaje portuario, la posición y acción de los personajes, el coche con el maletero donde esconder el futuro cadáver (pero también el movimiento circular de la cámara que avanza desde el plano de detalle del cañón de la pistola hasta el plano de conjunto), operan como imágenes-emblema procedentes del universo de referencia, pero que guardan poca relación con el resto de secuencias. No en vano, el segundo viaje recurre a los signos típicos del cine de terror: la narración alucinada en un entorno dominado por los claroscuros, la inmersión en espacios vedados a los mortales, la irresistible seducción de los habitantes que pueblan la noche, la música envolvente y, sobre todo, el sobresalto final, son las imágenes que constituyen la significación de los géneros del terror. Por no hablar de la comedia romántica que clausura el periplo narrativo del protagonista: chica que quiere escapar de una decisión impuesta, espacios luminosos y abiertos o el bappy end de la pareja en ese universo del que ya no saldrán nunca más.

Las diferencias respecto a Miedo, segunda wikipeli que fue co-dirigida por Jaume Balagueró junto a 6.034 usuarios son evidentes. Si Universos opera con «signos genéricos», Miedo opera con «conceptos genéricos». En otros términos, el film del afamado cineasta reconoce un universo de referencia y se sirve de sus códigos para construir un relato que «supone la apertura del conjunto con el que trabaja». Jaume Balagueró utiliza como interlocutor genérico al cine del terror psicológico que tan bien conoce y que tan buenos resultados le ha dado desde Los sin nombre (1999), pasando por Darkness (2002) o Frágiles (2005).

Así pues, al contrario que la anterior, la segunda wikipeli constituye por así decirlo un artefacto sólido, consistente consigo mismo y con el universo al que alude, universo que es reconocido y compartido por los usuarios del género. La creación de atmósferas inquietantes en los que la iluminación desempeña una función decisiva en virtud de la activa contraposición luz/sombra, la inestabilidad del protagonista ante unos acontecimientos que no comprende y que se desbordan en virtud de unos radicales giros que puntúan el tempo narrativo, son los elementos con que se construye la historia según un diseño genérico predeterminado de antemano y que está asentado en las anteriores experiencias del cineasta.

En definitiva, parafraseando a Levi-Strauss (1997, p. 39), puede decirse que Universos interroga a «una colección de residuos de obras humanas, es decir, a un sub-conjunto de la cultura» frente a Miedo, que más bien parece interrogar al universo conceptual del terror psicológico. O dicho en hermosa expresión del antropólogo, si la primera wikipeli elabora estructuras disponiendo acontecimientos (es a partir de la sucesión de elementos narrativos que puede llegar a comprenderse la frágil estructura que organiza internamente Universos), la segunda crea acontecimientos a partir de estructuras (es a partir del 
andamiaje constituido por los códigos del terror psicológico y su participación en un común fondo de semejanzas genérico, que Miedo distribuye los elementos narrativos en su superficie $)^{13}$.

\section{BRICOLAGE Y PARODIA}

En cuanto categoría profundamente vinculada con el bricolage, no parece casual la preponderancia de la parodia en estas prácticas colaborativas surgidas «desde abajo». Si existe alguna categoría en el que la significación reorganice el conjunto de partida, esa es sin duda la parodia.

$\mathrm{El}$ arranque de esa pequeña joya que es El jovencito Frankenstein (Young Frankenstein, Mel Brooks, 1976), sirve para caracterizar con nitidez la discursividad paródica. En una atestada clase de medicina, y ante la ensimismada disertación del profesor, uno de los alumnos se atreve a formular una pregunta. El docente, visiblemente contrariado al escuchar su nombre, amonesta al joven por lo desacertado de la pronunciación. No es «Frankenstein», irrumpe, sino «Fronkosteen». Su parentesco con el científico al que sin duda todos conocen, insiste, es accidental y prefiere ser recordado por sus pequeñas aportaciones a la ciencia antes que por su relación con un «brujo».

La inteligente presentación del protagonista -es visto de espaldas hasta que es pronunciado su nombre-, sirve a la vez para anticipar uno de los motivos que guían al protagonista de El jovencito Frankenstein. El brillante profesor de universidad intenta alejar la siniestra sombra de aquel temido familiar que creó vida a partir de carne muerta. El film mostrará sin embargo lo fútil del intento. Una vez descubierto el libro de memorias de su abuelo y reconocida la herencia, el cambio operado en el protagonista acontece precisamente en la verbalización del controvertido apellido. A partir de ese momento dejará de ser «Fronkosteen» para convertirse en un auténtico «Frankenstein».

El divertido sketch trasciende su función cómica y puede ser visto como un modelo reducido de la discursividad paródica: en pocas palabras, la parodia se constituye a partir de su confrontación con otro texto que le antecede. Elemento definitorio de la «estilización paródica» como argumentó Mijail Bajtin $(1987,1989)^{14}$, se trata como pusiera de relieve Gerard Genette (1989), de uno de los ejemplos más notables de «hipertexto», texto originado por deriva de un texto anterior. Conviene remarcar que se trata de una derivación que acontece según una norma que no es de repetición o imitación, sino de transformación; el texto paródico construye una significación nueva a partir de la alteración (reorganización) de un texto ya conocido. La parodia es una suerte de espejo distorsionador.

Los dos textos entablan por tanto un diálogo que implica, al igual que el apellido de nuestro héroe, un fondo de semejanza sobre el que se levanta la oposición. O, en otras palabras, para que la parodia germine debe instituirse una relación de similitud a la par que una disimilitud. Es en este sentido que establecen un vínculo que es tanto de interioridad como de exterioridad. Por un lado, el texto parodiado debe formar parte del discurso del texto parodiador, pero, por otro, el texto parodiador debe inscribir en su cuerpo una distancia respecto al texto parodiado.

Solo en virtud de este desvío puede considerarse cumplida la parodia, particularidad que la dota de sentido y a la vez la distingue de otra fórmula con la que guarda cierta cercanía pero que debe ser

\footnotetext{
${ }^{13}$ Esa es la famosa inversión en la relación entre la diacronía y la sincronía anotada por el pensador: «el pensamiento mítico, ese bricoleur, elabora estructuras disponiendo acontecimientos, o más bien residuos de acontecimientos, en tanto que la ciencia, 'en marcha' por el simple hecho de que se instaura, crea, en forma de acontecimientos, sus medios y sus resultados, gracias a las estructuras que fabrica sin tregua y que son sus hipótesis y sus teorías» (Levi-Strauss, 1998, p. 43).

${ }^{14}$ En palabras del teórico ruso, se trata del juego dialógico de dos lenguajes en el que «las intenciones del lenguaje que representa no coinciden con las intenciones del lenguaje representado, se le oponen, no representan el universo objetual real con la ayuda del lenguaje representado, como punto de vista productivo, sino por medio de su desenmascaramiento y destrucción» (Bajtin, 1989, pp. 179-180).
}

(C) Ediciones Universidad de Salamanca / CC BY - NC ND Fonseca, Journal of Communication, n. 14, 2017, pp. 215-227 
analizada como otra manifestación hipertextual: el pastiche ${ }^{15}$. A tenor de esta distinción, podría señalarse una preliminar distinción entre los ejemplos traídos a colación en estas páginas: Born of Hope y El cosmonauta se situarían en el territorio del pastiche frente a los anónimos videoclips musicales sobre Neo y Trinity, The Jedi Who Loved Me o Matrix Return. Y aun las dos wikipelis: Universos se decanta por lo paródico mientras que Miedo lo hace por el pastiche.

Tres cuestiones, al menos, podrían derivarse inmediatamente de esta somera caracterización. En primer lugar, la competencia lectora del espectador desempeña una función decisiva en la consideración de la categoría. Únicamente desde el reconocimiento del texto parodiado puede comprenderse la operación que lleva a cabo la parodia. Si, condición excepcional, el espectador de El jovencito Frankenstein desconoce las dos películas que dirigió James Whale en el ciclo de terror de la Universal durante la década de los años 30, auténtico referente del film más que el relato de Mary Shelley, no disfrutará de los guiños retóricos que ponen en marcha el tándem responsable de la adaptación paródica. Al igual que los espectadores que contemplen los amoríos de los protagonistas de la saga Matrix o se identifiquen con los actores anónimos que reinterpretan episodios de Star Wars: sin reconocimiento no existe goce paródico.

En segundo lugar y complementario de lo anterior, la parodia solo puede ser considerada en su interacción con el texto parodiado. Importante restricción que pone de relieve la paradoja que fecunda la fórmula desde la perspectiva de los géneros: al subordinarse al texto parodiado y por tanto a la adscripción genérica de este, la parodia carece de una identidad singular, no ocupa un espacio propio en el universo de los géneros al igual que puedan hacerlo, con todas las reservas posibles, fórmulas como el wéstern, el cine negro, el melodrama, etc. Antes bien, la parodia se disemina a lo largo y ancho de la cartografía genérica. No en vano, resulta evidente la habitual «desatención» del género parodiante respecto a las estructuras narrativas, temáticas y dramatúrgicas del texto parodiado. Parece como si el universo de partida sirviera únicamente de coartada para dejarse llevar por el gag, por la acumulación acéntrica de chistes y motivos tendentes a la dispersión.

En tercer lugar, el valor de distanciamiento de la parodia le otorga una notable autoconciencia reflexiva, es decir, una gran capacidad para hablar tanto de sí misma como, sobre todo, del texto al que remite. No en vano, la interacción tiene una repercusión directa también en este. Así, convertido en un «objeto de representación» en términos de Mijail Bajtin, el texto parodiado es convenientemente «desnaturalizado» y exhibido a la luz pública como un artefacto discursivo, como un objeto narrativo en el que se puede escudriñar su maquinaria significante y los rudimentos retóricos que lo hacen funcionar.

Esta triple caracterización puede servir para comprender mejor las numerosas parodias que pueblan el universo de la web. Pocos ejemplos sin embargo resultan tan ilustrativos como Troops (Kevin Rubio, 1997 ${ }^{16}$. El film pone en relación la saga de Star Wars con Cops, una célebre serie televisiva de la cadena FOX producida por Langley Prods, que comenzó su andadura en 1989 y que, a lo largo de aproximadamente 30 temporadas, acompañó a una dotación policial durante su patrulla diaria ${ }^{17}$.

Del primero utiliza sobre todo sus reconocibles signos icónicos: los poderosos y temidos soldados imperiales, los jawas, las naves, los parajes desérticos, pero también algunos de sus protagonistas principales (los familiares de Luke Skywalker), etc. La elaborada recreación de algunos efectos especia-

\footnotetext{
${ }^{15}$ La distinción ha sido puesta en valor pertinentemente por Fredric Jameson (1991, p. 43): «El pastiche es, como la parodia, la imitación de una mueca determinada, un discurso que habla una lengua muerta: pero se trata de la repetición neutral de esta mímica, carente de los motivos de fondo de la parodia, desligada del impulso satírico, desprovista de hilaridad y ajena a la convicción de que, junto a la lengua anormal que se toma prestada provisionalmente, subiste aún una saludable normalidad lingüística. El pastiche es, en consecuencia, una parodia vacía, una estatua ciega».

${ }^{16}$ Diferente es el caso de otro clásico del fanfilm, Batman: Dead End (Sandy Collora, 2003), ya que la mezcla del mundo de Batman con el de Alien y Predator tiene lugar en un universo genérico compartido.

${ }^{17}$ Sobre los orígenes del Docu-reality y la importancia desempeñada por Cops al respecto, consúltese (Misha, 2012).

(C) Ediciones Universidad de Salamanca / CC BY - NC ND Fonseca, Journal of Communication, n. 14, 2017, pp. 215-227
} 
les termina de clausurar el parentesco, como ilustra el primer encuadre; auténtico plano de situación, supone ante todo un extraordinario despliegue de aquellos elementos que permiten la inclusión del espectador en el universo de George Lucas. Nos encontramos en el Mar de las Dunas de Tatooine, y contemplamos una AT-ST Imperial (Transporte Explorador Todo Terreno) a la vez que varias motosjet atraviesan la pantalla a toda velocidad. Mientras que en el fondo despega una lanzadera imperial clase Lambda, en primer plano, los soldados de asalto comprueban sus equipos.

Del segundo, además de la reconocible sintonía de la serie original que ambientaba el peligroso contexto de los personajes (Bad Boys, composición original de Inner Circle) y anticipaba el universo narrativo y temático de lo que se desplegaría con posterioridad, retoma una notable retórica enunciativa del docu-reality a partir de ese pretendido "grado cero» de la comunicación televisiva en directo. Se trata de una retórica que adopta la textura estilística del «aquí y ahora» y que es certificada por los recursos habituales en la verosimilitud «sucia» de la emisión en directo: en primer lugar, la imagen titubeante de la cámara al hombro que resulta poco eficaz en términos de economía mostrativa pero que, en el caso televisivo, permite certificar la coincidencia espacio-temporal de la cámara (y subsidiariamente del espectador) con el acontecimiento. En segundo lugar, mediante el concurso de la voz over del protagonista del mediometraje, Capitán Jyanix Bach, que abre la narración desgranando su periplo vital y por qué se alistó tan joven al ejército imperial. Y, en tercer lugar, pero no menos importante, a través de la radical ruptura del universo diegético que acontece con la mirada a cámara de los personajes y la interpelación directa a un potencial espectador, afrenta impensable para el universo ideado por Georges Lucas. En un momento determinado, cuando los soldados imperiales asesinan a dos jawas sospechosos de robo, el protagonista se dirige a la cámara exigiendo que la apague.

Es precisamente en el intercambio de esos dos universos temáticos y narrativos tan alejados, nítido ejemplo de narrativa cross over según la tipología elaborada por Henry Jenkins (1992, p. 174), que se construye el mediometraje de Kevin Rubio. Y es precisamente también ahí donde radica el distanciamiento del artefacto resultante respecto de sus discursos referentes. Por un lado, al utilizar las estrategias habituales del docu-reality en un entorno ostensiblemente ficcional, denuncia la falsa objetividad sobre la que se construye el discurso televisivo en directo y pone en evidencia, como recordó Gerard Imbert (2008, p. 26), que la telerrealidad «construye su propio universo referencial, más allá de la verdad -se desenvuelve en lo verosímil-, dentro de una lógica de la seducción». Por otro lado, al situar la acción y los personajes del mundo fantástico en un contexto social y simbólico tan próximo a la realidad cotidiana del espectador que interpela, cuestiona el universo ficcional y los roles desplegados por Lucas en la saga espacial.

Se trata de una doble denuncia que, como anotara Linda Hutcheon (1993, p. 188), se constituye en la condición misma de la posibilidad de la parodia: trabajar «para poner en primer plano la política de la representación». Y aún más. En términos utilizados por Roland Barthes (1980, p. 11) en su análisis del acto de relectura, tanto Troops como todos aquellos artefactos paródicos de la Cultura de la convergencia manifiestan un notable potencial liberador: multiplicar en su diversidad y en su plural el texto referente. Las implicaciones derivadas afectan de manera determinante a una política de lo textual que tiene su repercusión inmediata en la construcción del lector/espectador. No estamos aquí ya, como anotara el semiólogo, en el terreno del consumo y los hábitos comerciales e ideológicos de nuestra sociedad, sino en el del juego, «ese juego que es el retorno de lo diferente». 


\section{CONCLUSIÓN}

En definitiva, la acertada polarización audiovisual entre las dinámicas top-down versus bottom-up anotada por Henry Jenkins, define con nitidez el enorme palimpsesto icónico que domina nuestra contemporaneidad. Se trata no obstante de una polarización que tiene su sustanciación en términos formales y estéticos diferenciados: a la manufactura profesional, altamente cualificada de las producciones audiovisuales ofrecidas «desde arriba» (véase cualquiera de los blockbusters que inundan las carteleras de nuestros cines), se contrapone la factura amateur, débilmente cohesionada, que se ofrece «desde abajo».

Dicha oposición, tradicionalmente comprendida en términos cuantitativos (lo uno no sería entonces más que un estado imperfecto de lo otro y, por tanto, secundario y con escaso interés formal), debe valorarse por el contrario en términos cualitativos: lo profesional constituye en su confrontación con lo amateur un eje plenamente categórico de notables consecuencias discursivas. No en vano, la traslación al ámbito audiovisual de las argumentaciones antropológicas desarrolladas por Levi-Strauss a propósito de la distinción entre el pensamiento mítico frente al pensamiento científico, posibilita un análisis en profundidad de los fenómenos colaborativos y anónimos más allá de su posición subsidiaria respecto de las grandes producciones industriales. De manera especial, permite valorar en mejores condiciones una de las principales categorías que pueblan el universo colaborativo de la web: la parodia, elemento esencial de la poética dialógica para Mijail Bajtin, cuya función parodiante reside precisamente en cuestionar el lenguaje representado para, desenmascarando sus intenciones, expandir la diversidad que subyace en el discurso referente.

\section{BiBLIOGRAFÍA}

Bajtin, M. (1987). La cultura popular en la Edad Media y en el Renacimiento. El contexto de François Rabelais. Buenos Aires: Alianza.

Bajtin, M. (1989). Teoría y estética de la novela. Madrid: Taurus.

Barthes, R. (1980). S/Z. Madrid: Siglo XXI.

Jenkins, H. (1992). Textual poachers. Television, fans and participatory culture. Londres: Routledge.

Jenkins, H. (2008). La cultura de la convergencia de los medios de comunicación. Barcelona: Paidós.

Genette, G. (1989). Palimpsestos. La literatura en segundo grado. Madrid: Taurus.

Hutcheon, L. (1993). La política de la parodia posmoderna. Criterios (edición especial de homenaje a Bajtín), 187-203.

Imbert, G. (2008). El transformismo televisivo. Postelevisión e imaginarios sociales. Madrid: Cátedra.

Jameson, Fredric (1991). El posmodernismo o la lógica cultural del capitalismo avanzado. Barcelona: Paidós.

Kavka, M. (2012). Reality TV. Edinburgh University Press.

Klinger, B. (2006). Beyond the multiplex; cinema, new technologies and the home. Berkeley: University of California Press.

Levi-Strauss, C. (1997). Elpensamiento salvaje. Colombia: Fondo de Cultura Económica.

Lipovetsky, G. y Serroy, J. (2009). La pantalla global. Barcelona: Anagrama.

Marcos Ramos, M. (2013). Esta película la hacemos entre todos. El cine colaborativo en España. Actas $V$ Congreso Internacional Latina de Comunicación.

Martínez, P. (2008). La cinematografía anarquista en Barcelona durante la Guerra Civil (1936-1939). Tesis doctoral. Barcelona: Universidad Pompeu Fabra.

Martos Núñez, E. (2006). «Tunear» los libros: series, fanfiction, blogs y otras prácticas emergentes de lectura. Revista OCNOS, 2, 63-77. 
Morán, C. (2007). Li(nk)teratura de Kiosko cibernético: fanfictions en la red. Cuadernos de Literatura, 12(23), 27-53.

Metz, C. (1973). Lenguaje y Cine. Barcelona: Planeta.

Roig, A. (2009). Cine en conexión. Producción industrial y social en la era 'cross-media'. Barcelona: UOCpress.

Roig, A.; Sánchez-Navarro, J. y Leibovitz, T. (2012). ¡Esta película la hacemos entre todos! ICONO 14, Año 10, Vol. 1, 25-40.

Wollen, P. (1988). Las dos vanguardias. En J. Pérez Perucha (coord.), Los años que conmovieron al cinema -las rupturas del 68- (pp. 303-312). Valencia: Filmoteca Valenciana.

Zunzunegui, S. (2008). La mirada plural. Madrid: Cátedra.

\section{Fonseca, Journal of Communication}

